\title{
Inspeção de uma Ponte de Acordo NBR 9452, na Cidade de Palmas-TO: Análise das Manifestações Patólogicas
}

\author{
CAMPOS, Vinícius Chaves [1], LABRE, Clara Vargas da Silva ${ }^{[2]}$, COSTA, Luan Pereira ${ }^{[3]}$, \\ CARVALHO, Daniel Iglesias de ${ }^{[4]}$
}

CAMPOS, Vinícius Chaves; et.al. Inspeção De Uma Ponte De Acordo NBR 9452, Na Cidade De Palmas-TO: Análise Das Manifestações Patólogicas. Revista Científica Multidisciplinar Núcleo do Conhecimento. Ano 03, Ed. 02, Vol. 02, pp. 98-109, Fevereiro de 2018. ISSN:2448-0959

\section{Resumo}

Foi realizado visitas técnicas em uma ponte rodoviária, situada no centro da cidade de Palmas- TO, para avaliar visualmente, de acordo a NBR 9452 (Inspeção de pontes, viadutos e passarelas de concretoProcedimento) a condição que se encontrava a obra de arte especial (OAE). Utilizou-se como critério de avaliação parâmetros estruturais, funcionais e de durabilidade, de acordo com a gravidade dos problemas detectados, que eram ocasionados por manifestações patológicas. As partes que compõem a infraestrutura da ponte não foram analisadas, por situarem abaixo do nível do solo. Na estrutura foi observado como patologias ninhos de concretagem, fissuras e trincas, bolores, eflorescências e possivelmente corrosão da armadura, mas esta última só pode ser dita com análises mais avançadas que visual. A ponte precisa de manutenções corretivas, para que a vida útil da obra de arte seja mantida.

Palavras-Chave: Ponte, Inspenção, Manifestações Patológicas.

\section{INTRODUÇÃO}

Desde eras passadas, os seres humanos precisam ultrapassar obstáculos para realizar suas tarefas, com esse propósito surgiram as primeiras pontes. As primeiras pontes feitas eram construídas de pedra ou madeira e possuíam dimensões pequenas normalmente, com o emprego de concreto e aço as pontes conseguiram vencer maiores vãos com o passar dos tempos. (MACHADO, SARTORTI;2010)

Ponte de maneira simplificada, nada mais é que como uma construção que possui o objetivo de transpor um obstáculo para permitir a continuidade uma via, independentemente de sua natureza. (DEBS; TAKEYA, 2009) 
Outra nomenclatura usada para referir ao termo ponte, segundo NBR 9452 é obra de arte especial.

Uma ponte pode ser classificada de diversas formas, como por exemplo, quanto a natureza do trafego (rodoviárias, ferroviárias, mistas, passarelas, etc), quanto ao método construtivo utilizado (pedra, madeira, concreto armado, concreto protendido, metais), quanto ao sistema estrutural da superestrutura em ponte em viga, arco, pórtico, estaiada e pênsil, etc.(DEBS;TAKEYA,2009)

$\mathrm{O}$ artigo em questão possui objetivo de avaliar a condição que se encontra uma ponte na cidade de Palmas- TO, por meio de análise visuais dos elementos que compõem a obra de arte especial.

As análises visuais serão realizadas para todos elementos observados na ponte e serão classificados por notas de 1 a 5 , que serão atribuídas de acordo com menor ou maior intensidade dos problemas observados.

O quadro abaixo demonstra o que cada nota representa para a condição do elemento observado.

\begin{tabular}{|c|c|}
\hline Nota de classificaçào & Condiçào \\
\hline 5 & Excelente \\
\hline 4 & Boa \\
\hline 3 & Regular \\
\hline 2 & Ruim \\
\hline 1 & Critica \\
\hline
\end{tabular}

Figura 1 - Classificação da condição da OAE

Os critérios de classificação dependerão do comprometimento que o elemento teve devido as manifestações patológicas.

Como resultados finais será demonstrado um quadro com as patologias vista em cada elemento, uma tabela para caracterizar todos componentes da ponte por notas, segundo aspectos estruturais, funcionais e de desempenho e um gráfico demonstrando a porcentagem que os diferentes tipos de patologia observados, tiveram na ponte.

Segundo NBR 9542, parâmetro estrutural são aqueles relacionados à segurança estrutural da ponte, com base em critérios de estado limite último e de utilização.

Parâmetro funcionais são aqueles relacionados aos fins que o elemento se destina, de modo que proporcione conforto e segurança aos usuários.

Parâmetros de durabilidade estão associados com o cumprimento das funções da estrutura para vida útil planejada. 
A ponte rodoviária situa-se na Avenida NS2, sentindo Norte-Sul, próximo ao espaço cultural e que transpõe o Córrego Brejo Comprido. Quanto ao método construtivo, viu-se o emprego do concreto armado, porém parecia visualmente que alguns elementos eram pré-moldados. Em relação ao sistema estrutural, estávamos diante de uma ponte em viga. A figura a seguir mostra a Ponte vista por cima da superestrutura. 


\section{Revista Científica Multidisciplinar Núcleo do Conhecimento - RC: 13579 - ISSN: 2448-0959}

https://www.nucleodoconhecimento.com.br/engenharia-civil/inspecao-de-uma-ponte

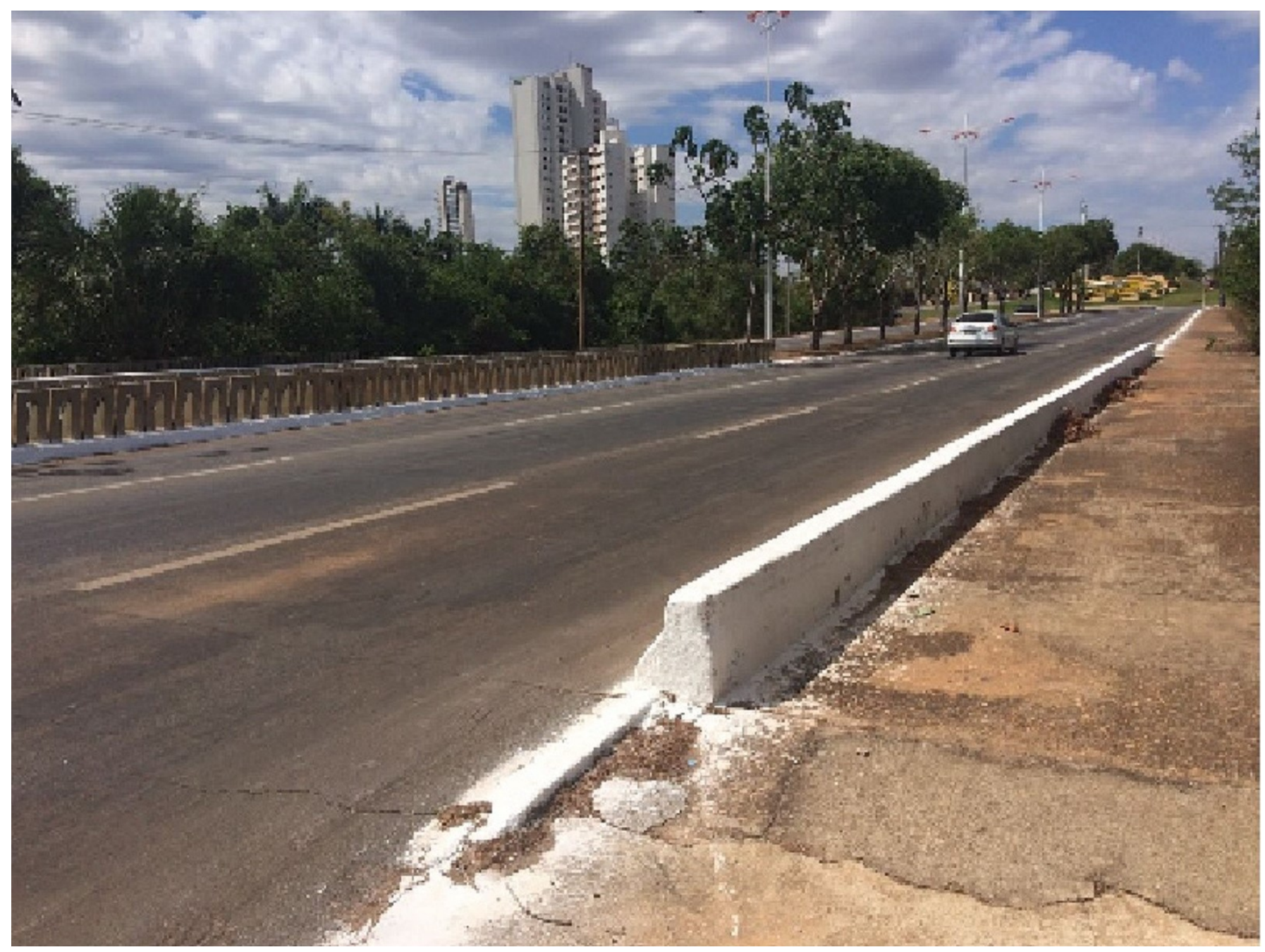

Figura 2 - Ponte estudada na cidade de Palmas- TO

Segundo, Ripeer, Souza(1998) Patologia em estruturas é um campo recente de estudo da engenharia que estuda as origens, formas de manifestações, consequências e mecanismos de falhas dos sistemas das estruturas.

Será tratado de forma resumida os conceitos de manifestações patológicas observadas na estrutura ou que poderiam ocorrer em um período curto de tempo.

A umidade não é apenas um fator que ocasiona patologias, ela também age como um meio para que diversas patologias na construção ocorram, de forma que é um fator essencial para o aparecimento de eflorescências e bolores. (VERÇOSA,1991 apud DE SOUZA,2008)

O Bolor, popularmente conhecido como mofo está relacionado ao desenvolvimento de fungos ocasionados pela presença de umidade e por ventilação e insolações inadequadas.(DE SOUZA,2008)

A eflorescência costuma se originar por meio de precipitações e deve existir três fatores para que essa manifestação ocorra que são os teores de sais solúveis nos componentes, presença de água e pressão hidrostática que faz com que a migração da solução aconteça em direção a superfície. A superfície do 
elemento como um concreto pode ficar esbranquiçada devido a presença de sais. (DE SOUZA,2008)

O desgaste superficial do concreto são fatores de origem física que podem deteriorar a superfície do concreto e podem ocorrer de três formas que são a abrasão, erosão e cavitação.(LAPA,2008)

A abrasão é um desgaste do concreto pelo atrito das partículas sólidas, de forma que a resistência superficial e a dureza do concreto influenciam no aparecimento ou não da abrasão. (LAPA,2008)

Erosão é o desgaste do concreto, provocado pelo carreamento de partículas finas pela ação da água. (LAPA,2008)

Cavitação é a deterioração do concreto pela implosão de bolhas de vapor de água quando a velocidade ou direção do líquido escoado sofrem mudanças bruscas de direção. (LAPA,2008)

As fissuras são oriundas normalmente por tensões geradas por cargas ou pela movimentação de materiais ou componentes estruturais. (VALLE,2008)

De acordo com a espessura da abertura, as fissuras podem se classificar como fissura, trinca, rachadura, fenda ou brecha. (DE OLIVEIRA,2012)

O quadro a seguir indica os limites que vão as espessuras das aberturas, para se denominar com determinado tipo de classificação.

\begin{tabular}{|l|l|}
\hline Anomalias & Abertura(mm) \\
\hline Fissura & ate 0,5 \\
\hline Trinca & de 0,5 a 1,5 \\
\hline Rachadura & 1,5 a 5,0 \\
\hline Fenda & 5,0 a 10,0 \\
\hline Brecha & acima de 10 \\
\hline
\end{tabular}

conforme abertura

Figura 3 - Classificação da anomalia

Há ausência de juntas de dilatação em obras de arte pode gerar o aparecimento de fissuras também, visto que segundo Ferreira, 2013 juntas de dilatação foram concebidas para dar continuidade a dois elementos contíguos, acomodando os movimentos da estrutura sem que haja transmissão de esforços. Em obras de 
artes como pontes costumam servir de transição entre tabuleiros e encontros, ou entre tabuleiros contíguos e costumam localizar no ponto mais frágil da estrutura. (FERREIRA,2013)

Os vazios ou nichos de concretagem, conhecidos popularmente como bicheiras são ocasionadas por falhas no processo de concretagem da estrutura, que costumam ocorrer no lançamento ou adensamento. Outra causa são erros no detalhamento da armadura, onde ocorre a retenção da brita e a passagem apenas da argamassa, de forma que onde houve a retenção da brita, costuma ficar um vazio de concretagem. (FIGUEROLA,2006)

A água é necessária para que ocorra o processo de corrosão (como eletrólito) e para o processo de carbonatação ao preencher parcialmente os poros do concreto. A corrosão da armadura, inicia-se com o rompimento da película passivadora , que inicia-se com a carbonatação do aço dentro do concreto. Esse processo é expansivo e provoca expansão, fissuração e destacamento do concreto de cobrimento (METHA; MONTEIRO,2008) devido a reação do oxido de ferro que passa a ocupar espaço e pressionar o concreto (RIPPER,SOUZA,1998).

Em outras palavras, podemos dizer que os principais fatores que proporcionam a corrosão são o meio na qual a estrutura está inserida e cobrimentos inadequados.

Caso, se confirme esta manifestação patológica o reparo é fundamental, pois a perda da seção de aço pode comprometer a capacidade estrutural da obra de arte.

\section{PROCEDIMENTOS}

Na visita à ponte houve análise visuais do estado que se encontrava cada elemento construtivo. A seguir será demonstrado um croqui da Ponte, para facilitar o entendimento da mesma. 


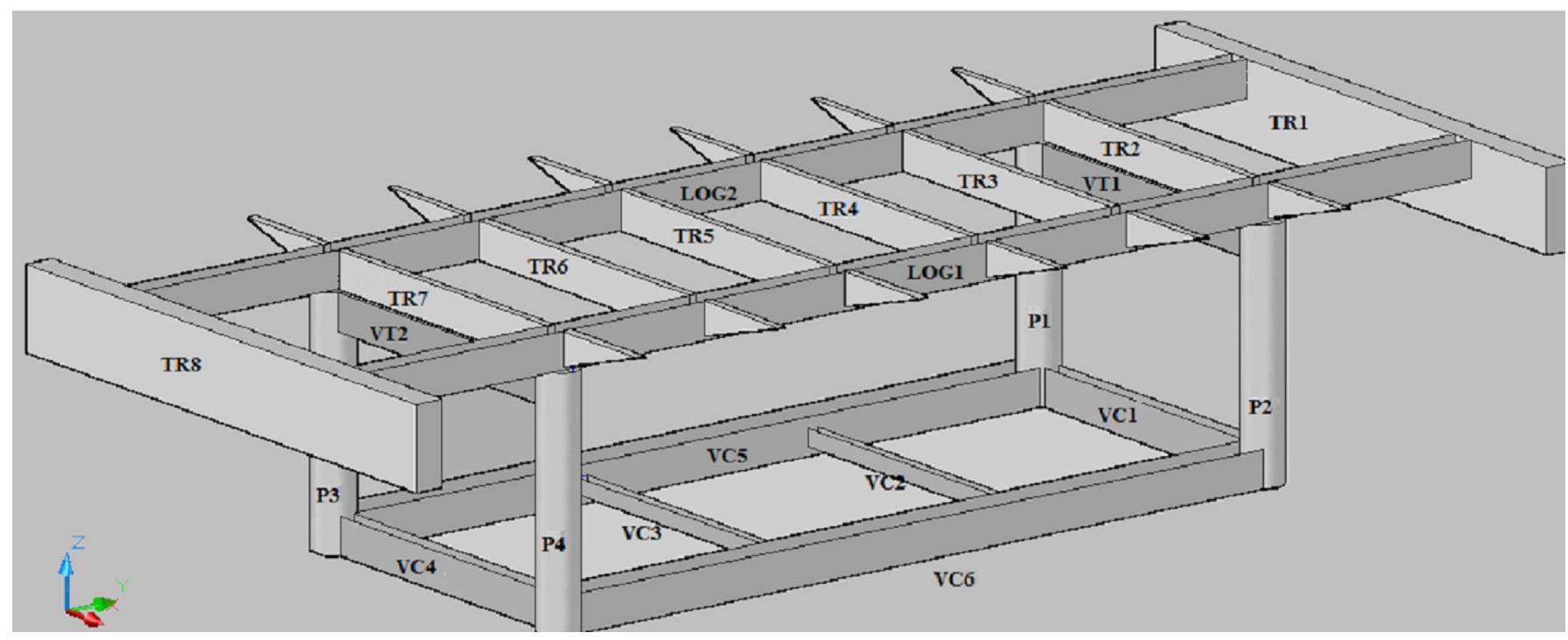

Figura 4 - Croqui da ponte avaliada

Denominou as vigas da cinta com a nomenclatura VCS, os pilares de P, longarinas de LOG, transversinas de TR, viga de travamento de VT, tabuleiro de TAB.

Com a análise visual, preencheu um quadro com as manifestações patológicas vistas em cada elemento. Com base nas informações do quadro avaliou as condições dos componentes com notas segundo aspectos estruturais, funcionais e de desempenho. Com as informações, realizou-se um gráfico que indicava a porcentagem que determinada patologia foi observada na ponte. Com todos estes resultados foi fornecido um parecer visual da situação que se encontrava a ponte.

\section{RESULTADOS}

A ponte possuía 30 metros de comprimento por 14,15m de largura, contava com guarda-corpo constituído por 66 elementos vazados em ambos os lados do pavimento, guarda-roda em uma lateral, calçada para pedestre em uma lateral da obra de arte com dois e oitenta de largura por trinta metros de comprimento, dois locais para acessar a mesoestrutura da ponte, seja para realizar visitas ou manutenções. A drenagem da ponte era realizada por 21 tubos de 100. Não havia próximo à ponte, placas para indicar a presença dela e não foi identificado juntas de dilatação.

No pavimento da ponte haviam três faixas para veículos com cada uma possuindo 3,5m de largura.

A seguir estará um quadro indicando as manifestações patológicas encontradas nos elementos da obra de arte.

Tabela 1 - Quadro com as manifestações patológicas

\begin{tabular}{|c|c|}
\hline Elemento & Manifestações Patológicas \\
\hline P1 & Fissuras, bolor \\
\hline P2 & Fissuras, bolor, ninho de concretagem \\
\hline
\end{tabular}




\begin{tabular}{|c|c|}
\hline $\mathbf{P 3}$ & $\begin{array}{l}\text { Fissuras, brechas bolor, armadura exposta no pé e } \\
\text { topo, abrasão }\end{array}$ \\
\hline $\mathbf{P 4}$ & $\begin{array}{c}\text { Fissuras, brechas bolor, abrasão, armadura exposta } \\
\text { no pé }\end{array}$ \\
\hline VC1 & Fissuras, brechas, armadura exposta, abrasão \\
\hline VC2 & Fissuras, trincas, bolor \\
\hline VC3 & Fissuras, abrasão \\
\hline VC4 & $\begin{array}{l}\text { Fissuras, rachaduras, brechas, abrasão, armadura } \\
\text { exposta }\end{array}$ \\
\hline VC5 & Fissuras, bolor, abrasão \\
\hline VC6 & Fissuras, trincas, abrasão \\
\hline VT1 & Fissuras, Bolor \\
\hline VT2 & Fissuras, bolor, abrasão \\
\hline TR1 & Fissuras, bolor, eflorescência, estalactite \\
\hline TR2 & Fissuras, Bolor \\
\hline TR3 & Fissuras, Bolor \\
\hline TR4 & Fissuras, Bolor \\
\hline TR5 & Fissuras, Bolor \\
\hline TR6 & Fissuras, Bolor \\
\hline TR7 & Fissuras, Bolor \\
\hline TR8 & Fissuras, bolor, eflorescência \\
\hline LOG1 & Fissuras, bolor \\
\hline LOG2 & Fissuras, bolor \\
\hline TAB & Fissuras, bolor, eflorescência \\
\hline Guarda-Corpo & Fissuras, brechas \\
\hline Pista de rolamento & Trincas \\
\hline
\end{tabular}

$\mathrm{Na}$ mesoestrutura da Ponte, foi observado que todos os pilares possuíam fissuras, normalmente de pequenos comprimentos e espessuras, porém no curto período de pesquisa não se pode determinar se eram fissuras ativas ou passivas. Outra manifestação patológica observada em todos pilares foi a presença de bolor. No Pilar que denominamos P2 é possível observar indícios de ninho de concretagem em sua base, conforme a imagem a seguir. 


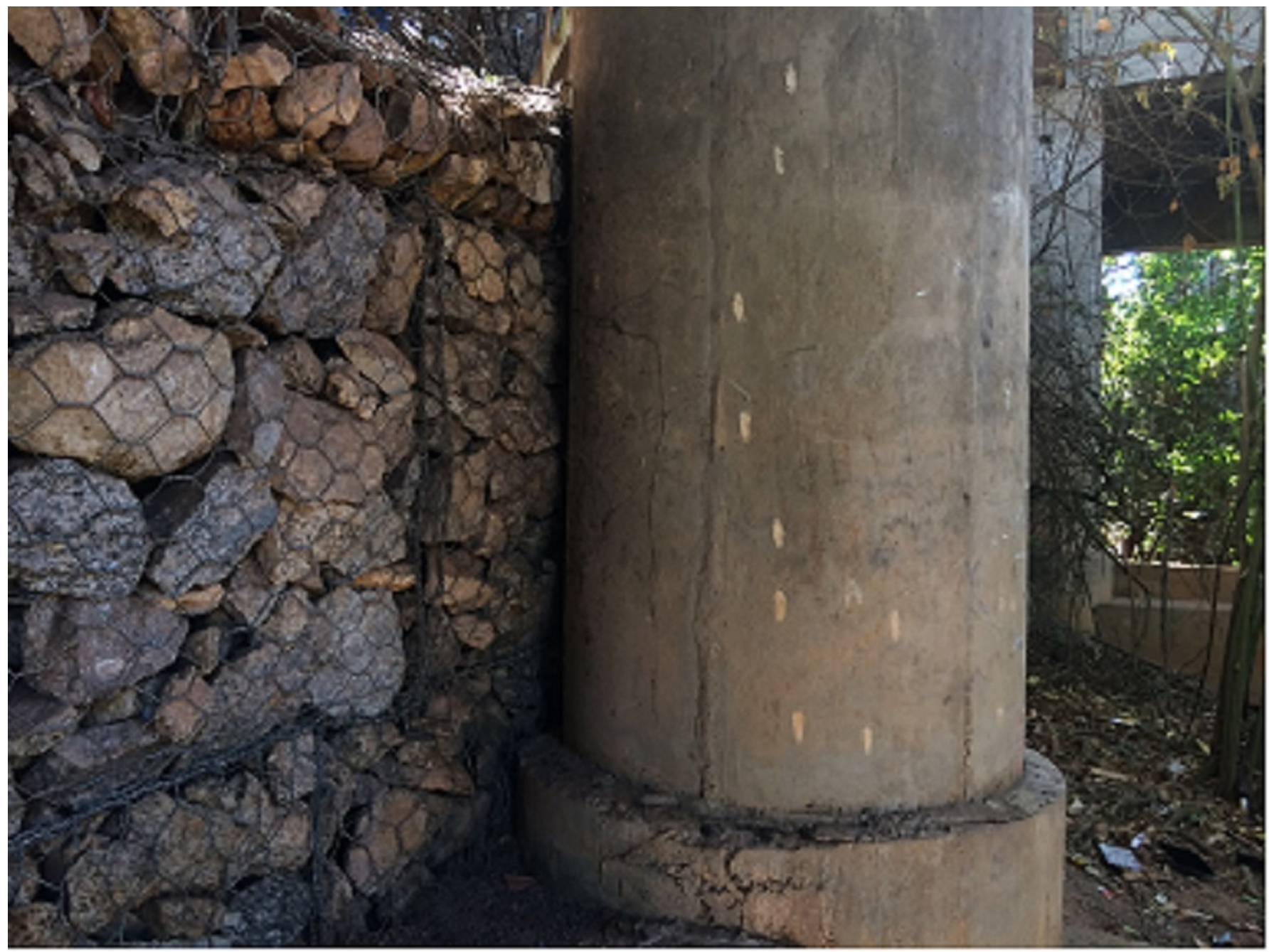

Figura 5 - Ninho de Concretagem no P2

No pilar denominado P4 foi identificado desplacamento do concreto, de forma que as armaduras estavam expostas. A imagem a seguir demonstra a situação descrita. 
Revista Científica Multidisciplinar Núcleo do Conhecimento - RC: 13579 - ISSN: 2448-0959

https://www.nucleodoconhecimento.com.br/engenharia-civil/inspecao-de-uma-ponte

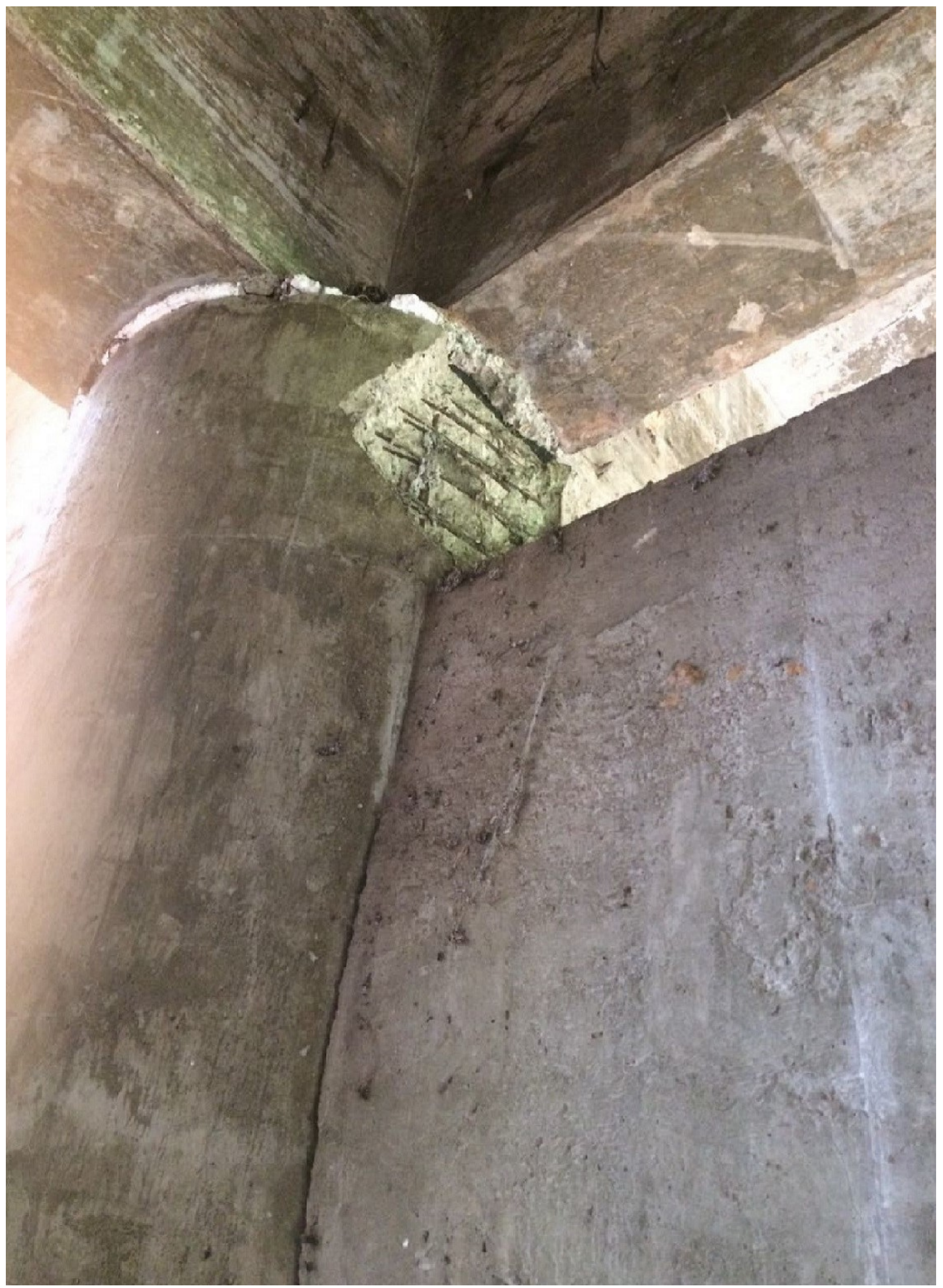


Figura 6 - Desplacamento do concreto no P4

As vigas cintas que denominamos VC, todas possuem fissuras. Já o desgaste superficial apareceu em todas, com exceção da VC2.

Nas duas longarinas da superestrutura foi visto que ambas possuíam fissuras e bolor.

Todas transversinas possuíam fissuras e bolor. A TR8 apresentou a mais a manifestação patológica da eflorescência e TR1 apresentou eflorescência e estalactite.

As duas vigas de travamento apresentaram fissuras e bolor, porém a TR2 também apresentou desgaste superficial.

Destaca-se que há grande quantidade de problemas causados pelo bolor, deve-se pelo fato de as partes da superestrutura e mesoestrutura receberem pouca irradiação solar e pelo fato de termos o córrego brejo comprido passando embaixo da Ponte, onde o a umidade local é elevada.

Em relação a drenagem da Ponte foi observado 21 tubos de 100mm, estando alguns deles obstruídos com sujeiras como folhas, pedras, plásticos e resíduos orgânicos e inorgânicos. Embora alguns tubos estivessem obstruídos, como os guarda corpos da ponte eram constituídos por 66 elementos vazados de ambos os lados, conforme a figura abaixo, a qualidade da drenagem funcionava de forma a desempenhar seu papel e isso foi observado em alguns dias de intensidade pluviométrica elevada. 


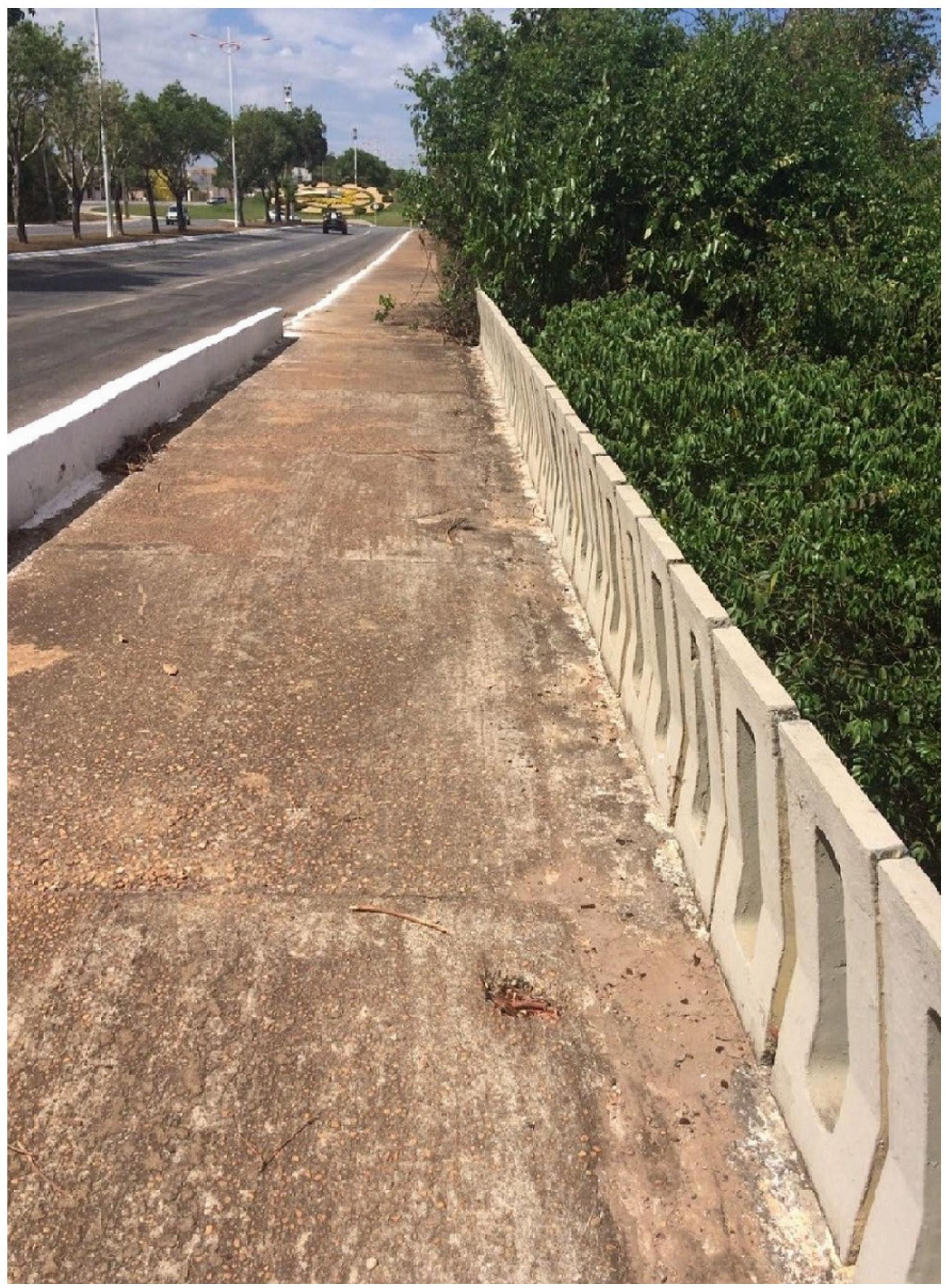


Figura 7 - Guarda corpo da ponte

Além das tubulações a drenagem contava com uma rota pelo pavimento, para escoar as aguas provenientes de precipitações sobre o mesmo, conforme demonstra a figura a seguir. 


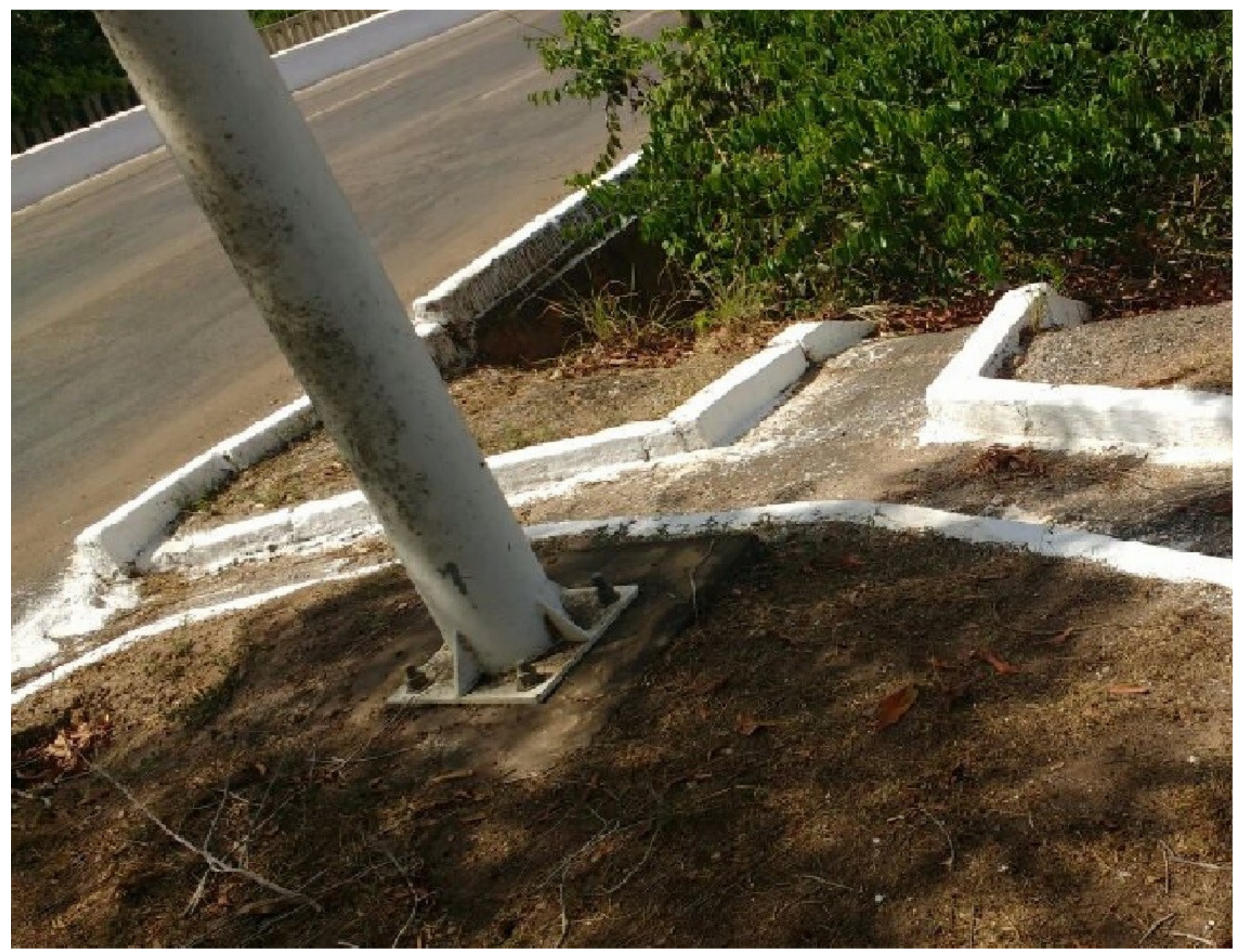

Figura 8 - Drenagem no pavimento

Não foi observado juntas de dilatação na ponte, seja elas abertas, de betume modificadas, juntas seladas com material elástico, juntas com placas metálicas deslizantes, etc, mas havia trincas na pista de rolamento, por isso desconfiou-se que poderiam haver juntas de dilatação enterradas degradadas, mas essa informação só poderia ser respondida com segurança por meio de análise do projeto.

Na ponte havia elementos fundamentais neste tipo de obra de arte que eram os guarda-rodas e guardacorpos e ambos estavam em estado conservado. As únicas manifestações patológicas observadas foram fissuras em alguns guarda-corpos e que dois dos 132 elementos vazados que o constituíam estavam quebrados, conforme figura abaixo. 


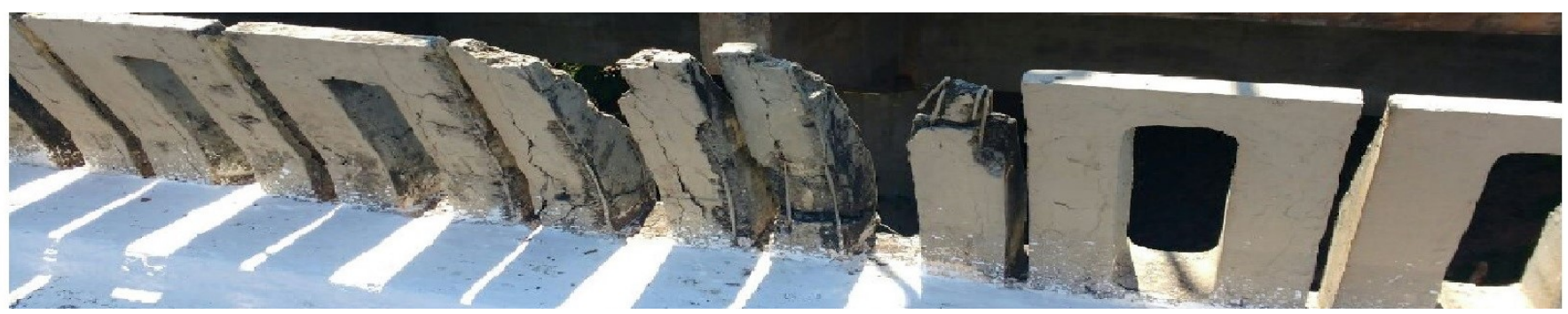

Figura 9 - Guarda corpo danificado

Foi observado na ponte que os aparelhos de apoio eram de um material diferente do existente na estrutura da ponte, aparentemente parecia ser algum elastomero e estava em bom estado de uso.

Demonstra-se preocupação com a corrosão na ponte, visto que fissuras e desgaste superficial em concreto facilita a entrada da água no concreto. Mas essa manifestação patológica só poderia ser identificada por meio de indicadores de carbonatação como a fenolftaleína e timolftaleína e por meio de ensaios mais apurados.

\section{CARACTERIZAÇÃO DOS COMPONENTES COM BASE EM PARÂMETROS ESTRUTURAIS, FUNCIONAIS E DE DURABILIDADE}

Foi avaliado cada elemento da ponte com notas de 1 a 5 segundo parâmetros estruturais, funcionais e de durabilidade. $\mathrm{O}$ anexo $\mathrm{E}$ que se chama referência de classificação da OAE foi usado como base para indicar as notas.

A classificação do elemento quanto a principal, secundário e complementar influencia muito na nota, de modo que uma mesma manifestação patológica terá notas diferentes dependendo da classificação do componente da obra de arte especial.

A NBR 9452 classifica os elementos da seguinte forma:

- Elemento principal (P) -cujo dano pode ocasionar colapso parcial ou total da obra;

- Elemento secundário (S) - cujo dano pode ocasionar ruptura localizada;

- Elemento complementar (C) -cujo dano não causa nenhum comprometimento estrutural, apenas funcional na OAE.

Como elementos principais nesta obra de arte, teremos os pilares, longarinas. Como secundários teremos as transversinas. Os elementos complementares são viga de travamento, viga cinta, guarda rodas e guardacorpos.

A tabela a seguir indica a classificação do estado em que se encontra os componentes da ponte observado.

Tabela 2 - Classificação da condição dos componentes da OAE

\section{Elemento}

P1
Nota de 1 a 5 


\begin{tabular}{|c|c|}
\hline $\mathrm{P} 2$ & 4 \\
\hline P3 & 3 \\
\hline $\mathrm{P} 4$ & 3 \\
\hline $\mathrm{VC} 1$ & 4 \\
\hline $\mathrm{VC} 2$ & 4 \\
\hline VC3 & 4 \\
\hline $\mathrm{VC} 4$ & 4 \\
\hline VC5 & 4 \\
\hline VC6 & 4 \\
\hline VT1 & 4 \\
\hline VT2 & 4 \\
\hline TR1 & 4 \\
\hline TR2 & 4 \\
\hline TR3 & 4 \\
\hline TR4 & 4 \\
\hline TR5 & 4 \\
\hline TR6 & 4 \\
\hline TR7 & 4 \\
\hline TR8 & 4 \\
\hline LOG1 & 4 \\
\hline LOG2 & 4 \\
\hline TAB & 4 \\
\hline Sinalização & 2 \\
\hline Guarda-roda & 4 \\
\hline Guarda-corpo & 3 \\
\hline Pista de rolamento & 5 \\
\hline
\end{tabular}

Com o intuito de facilitar o parecer da ponte, classificou as notas por superestrutura, mesoestrutura, sinalização, pista de rolamento e segurança (guarda-corpo e guarda-roda). A menor nota atribuída a um dos elementos semelhantes é a que prevalece como resultado da avaliação.

Os elementos que compõem superestrutura são tabuleiro, longarina, transversinas. Já os que compõem a mesoestrutura são os pilares, viga de travamento e viga cinto. 
A avaliação de acordo com estas estruturas, está na tabela abaixo.

Tabela 3 - Classificação resumida da condição da OAE

\begin{tabular}{|c|c|}
\hline Estrutura & Nota de 1 a 5 \\
\hline Superestrutura & 4 \\
\hline Mesoestrutura & 3 \\
\hline Sinalização & 2 \\
\hline Segurança & 3 \\
\hline Pista de rolamento & 5 \\
\hline
\end{tabular}

Apesar de não existir placas de sinalização a avaliação ficou com nota 2 na condição de ruim, pois o local não fornecia grandes riscos aos usuários da via.

\section{AVALIAÇÃO PERCENTUAL DAS MANIFESTAÇÕES PATOLÓGICAS OBSERVADAS NA PONTE}

Para obter este resultado, contabilizou todos elementos observados, de forma a ver percentualmente em quantos aparecia determinada patologia.

Ao somar pilares, longarinas, transversinas, tabuleiro e demais elementos totalizou 26 elementos. O quadro abaixo demonstra a quantidade de cada manifestação patológica observada, juntamente com a porcentagem que isto representa.

Tabela 4 - Quadro com mapeamento das manifestações patológicas

\begin{tabular}{|c|c|c|}
\hline Manifestação Patológica & Quantidade de Ocorrência & \% de ocorrência \\
\hline Fissuras & 24 & $92,31 \%$ \\
\hline Trincas & 3 & $11,54 \%$ \\
\hline Rachaduras & 1 & $3,85 \%$ \\
\hline Brechas & 5 & $19,23 \%$ \\
\hline bolor & 19 & $73,08 \%$ \\
\hline ninho de concretagem & 1 & $3,85 \%$ \\
\hline Desplacamento do concreto- & 5 & $19,23 \%$ \\
\hline Armadura exposta & & \\
\hline Abrasão & 8 & $30,77 \%$ \\
\hline Eflorescência & 3 & $11,54 \%$ \\
\hline Estalactite & 1 & $3,85 \%$ \\
\hline
\end{tabular}


O gráfico abaixo correlaciona a manifestação patológica pela \% de ocorrência, com intuito de demonstrar as informações contidas no quadro, de forma mais simplificada. 


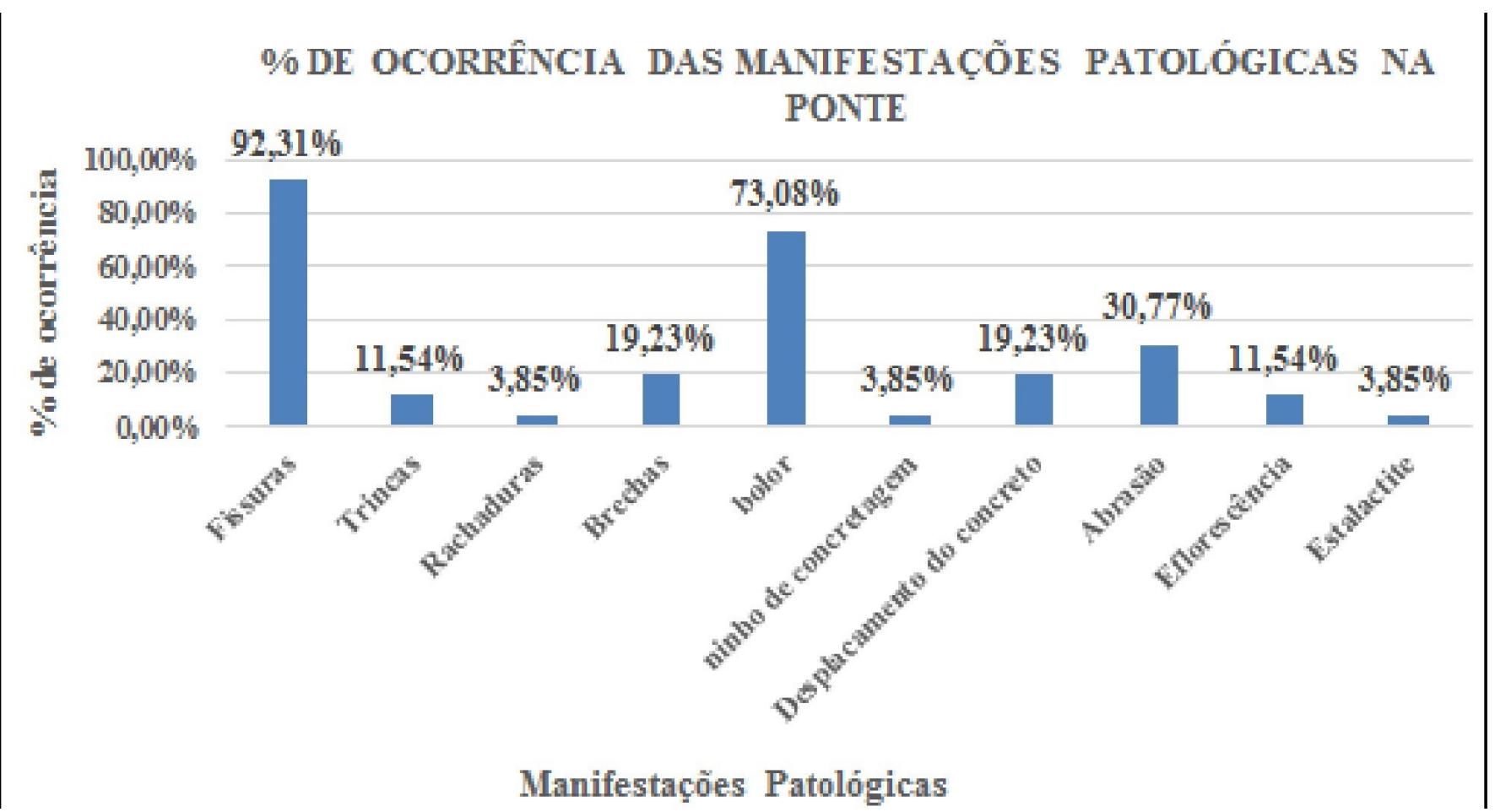

Figura 10 - Gráfico com mapeamento das manifestações Patológicas na OAE

\section{CONCLUSÃO}

Com as visitas técnicas à Ponte, observou-se que havia manifestações patológicas em praticamente todos elementos da superestrutura e mesoestrutura, porém eram de magnitude de risco que não comprometem a utilização dessa obra de arte atualmente.

Esta Ponte poderia estar em condições de uso melhores, se manutenções preventivas estivessem sido realizadas, porém infelizmente este tipo de manutenção são raras no Brasil, visto que as preocupações com essas estruturas só começam a existir com aparecimentos de sintomas das manifestações patológicas das estruturas.

Com esta Ponte o cenário não é diferente, pois aparentemente não foi realizado manutenções preventivas e com os aparecimentos de certos sintomas patológicos, a estrutura demonstra que as necessidades de manutenções corretivas são necessárias para garantir a vida útil esperada da estrutura.

\section{REFERÊNCIAS BIBLIOGRÁFICAS}

DE OLIVEIRA, Alexandre Magno. Fissuras, trincas e rachaduras causadas por recalque de diferencial de fundações. 2012.

DE SOUZA, Marcos Ferreira. Patologias ocasionadas pela umidade nas edificações. 2008.

DEBS, El; KHALIL, Mounir; TAKEYA, Toshiaki. Introdução às Pontes de Concreto-. São Carlos, 2009. 
FERREIRA, Carlos Manuel Sebastião. Tipologia, instalação, funcionamento e manutenção de diversos tipos de juntas de dilatação em Obras de Arte. 2013. Tese de Doutorado. Instituto Superior de Engenharia de Lisboa.

FIGUEROLA, Valentina. Vazios de Concretagem. Revista Techne 109 - abril, 2006.

LAPA, José Silva. Patologia, recuperação e reparo das estruturas de Concreto. Especialização em Construção Civil. UFMG. Belo Horizonte, 2008.

MACHADO, Rafael Navalho; SARTORTI, Artur Lenz. Pontes: Patologias dos Aparelhos de Apoio. In: Artigo (VI Congresso Internacional sobre Patologia e recuperação de estruturas). UNASP-Engenheiro Coelho, São Paulo. 2010.

MEHTA, P. K; MONTEIRO, P. J. M. Concreto: microestrutura, propriedades e materiais. $2^{\circ}$ edição. São Paulo: IBRACON, 2008

RIPPER, Thomaz; SOUZA, Vicente Custódio de. Patologia, recuperação e reforço dc estruturas de concreto. São Paulo: Editora Pini, 1998.

VALLE, Juliana Borges de Senna. Patologia das Alvenarias-Causa/Diagnóstico/Previsibilidade. Belo Horizonte, MG. Trabalho de Conclusão de Curso de Pós-Graduação. Universidade Federal de Minas Gerais, 2008. 81p, 2008.

${ }^{[1]}$ Graduação em Engenharia Civil pelo Centro Universitário Luterano de Palmas CEULP/ULBRA

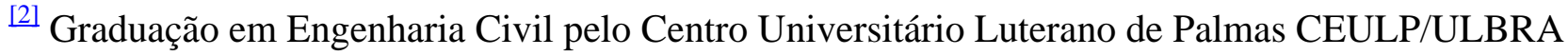

${ }^{[3]}$ Graduação em Engenharia Civil pelo Centro Universitário Luterano de Palmas CEULP/ULBRA

${ }^{[4]}$ Professor de engenharia civil na Universidade Federal do Tocantins - UFT e do Centro Universitário Luterano de Palmas - ULBRA. Professor convidado no ITPAC. Graduação em Engenharia Civil pela Universidade Presbiteriana Mackenzie, especialização em docência do ensino superior e Mestrado em Engenharia Ambiental pela UFT

\section{PUBLIQUE SEU ARTIGO CIENTÍFICO EM:}

https://www.nucleodoconhecimento.com.br/enviar-artigo-cientifico-para-submissao 